\title{
NÃO ENTENDER, O CANTEIRO DE OBRAS \\ A PEDAGOGIA (IM)POSSÍVEL
}

\author{
Luciana di Leone \\ UFRJ
}

RESUMO: A partir da experiência da sala de aula do professor Raúl Antelo é possível pensar em um dispositivo que, não se constituindo em um método em sentido tradicional, poderia ser pensado com uma pedagogia (im)possível. Colocando no centro desse dispositivo o "não entendimento", é possível analisar, por um lado, a derrocada da centralidade identitária, paternalista e de herança e propulsor da vertigem, a voracidade e o dispêndio e, por outro, a aparição nessa derrocada das ruínas que permitem 0 tecido de novas ficções críticas, de redes textuais e de novas genealogias, menos paternais e mais maternas e infantis.

PALAVRAS-CHAVE: Pedagogia; Genealogia; arquifilologia.

NOT UNDERSTANDING, THE FLOWERBED OF WORKS

THE (IM)POSSIBLE PEDAGOGY

ABSTRACT: From Professor Raul Antelo's classroom experience it is possible to think about a device that, once it is not constituted by a traditional method, could be thought of as an (im)possible pedagogy. Putting in the center of this device the "non comprehension", it is possible to analyze, from one hand, the downfall of identity, paternalistic and of heritage centrality and a propeller of the vertigo, the voracity and the expenditure and, from the other hand, the appearance of the ruins in this downfall that permit the weaving of new critical fictions, textual networks and of new genealogy, less paternalistic and more maternal and infantile.

KEYWORDS: Pedagogy; Genealogy; Archiphilology.

Luciana di Leone é Professora Adjunta do departamento de Ciência da Literatura na Universidade Federal do Rio de Janeiro. 


\title{
NÃO ENTENDER, O CANTEIRO DE OBRAS A PEDAGOGIA (IM)POSSÍVEL $\underline{1}$
}

\section{Luciana di Leone}

\author{
Dos momentos \\ en toda su desaparición \\ Dos momentos \\ como los únicos momentos
}

Arturo Carrera, La inocencia

\section{DOIS MOMENTOS OU UMA SENSAÇÃO E UMA IMAGEM}

Escutei Raúl Antelo pela primeira vez em 2001, convidado para dar uma palestra na Universidade de Buenos Aires, onde eu cursava a graduação. A segunda vez que o escutei foi em 2005, no Brasil, no começo da minha vida como estrangeira. No entanto, essa primeira e essa segunda escuta, que consegui diferenciar só depois de fazer cálculos de datas e exercícios mnemotécnicos, estiveram durante anos totalmente misturadas para mim. Misturadas em uma nebulosa de memória, que ainda me leva a dizer que não, não lembro nada das minhas primeiras escutas do Raúl. Ou quase. Pois nessa nebulosa se destacam dois grumos: uma sensação e uma imagem, que ao mesmo tempo se confundem entre si.

Lembro que não entendi nada, ou seja, lembro da sensação de "não entender". E lembro da imagem, enunciada em português, do "canteiro de obra" (imagem que convocava ao mesmo tempo destruição e construção, na modernização das cidades). Sensação e imagem que voltam uma e outra vez, sempre juntas, sempre misturadas, atravessadas por línguas e geografias diversas, pela crise argentina de 2001 e a minha crise geográfica de 2005, pelas construções ruinosas das salas de aula da UBA e da UERJ. Sem lembrar lembrando, eu recolhi isso: um não entender, e um canteiro de obras.

A pobreza da experiência dessas falas do Raúl - eu não sou capaz de contar nada do que ali foi dito - depois de dez anos, continua a mesma. Eu guardei a pobreza (no começo a suportei, depois passei a amá-la, como acontece com o sotaque). Continuo sem entender nada, e continuo vendo sempre o mesmo canteiro de obras, nos seus textos, nas suas aulas. E além. $O$ não saber e o canteiro se tornaram um horizonte - paradoxalmente - exemplar, procura de uma

\footnotetext{
${ }^{1}$ Comunicação apresentada em 30 de outubro de 2014, no Museu de Arte do Rio (MAR). Mesa: "Ficções críticas: derivas".
} 
atitude de leitura, e de um modo de posicionamento ético no enfrentamento com os textos, e com a instituição.

Dai que eu só possa, e só queira, no final das contas, falar dessa sensação e dessa imagem como dispositivos da uma pedagogia. Da única pedagogia possível para mim, e quando falo de mim, nomeio - não exatamente, mas nomeio - a minha geração, a geração de filhos - sem pai, como corresponde aos filhos deste século, e ainda mais aos filhos dos 70/80 na América Latina. Ou seja, de uma pedagogia para apátridas, que Raúl - não tão comumente mencionado como educador - leva às suas consequências mais extremas.

Sabemos que a universidade só se distância do jardim de infância pela aplicação confiante da ideia de formação evolutiva que, insistindo na dicotomização natureza/cultura, caracteriza-se por um longo processo de domesticação e controle de toda pulsão, de toda "atração irresistível"; sabemos que um adulto só se distância de uma criança pelos mesmos motivos, e o ocidente do oriente, e Europa da América latina, e assim por diante. Neste sentido, a imagem do canteiro de obra como força no ensino universitário não traz senão a reflexão benjaminiana sobre "material educativo infantil". Diz, lembremos, o belo texto de Rua de mão única, "Canteiro de obras":

\begin{abstract}
Elucubrar pedantemente sobre a fabricação de objetos - material educativo, brinquedos ou livros - que fossem apropriados para crianças é tolice. Desde o lluminismo essa é uma das mais bolorentas especulações dos pedagogos. Seu enrabichamento pela psicologia impede-os de reconhecer que a Terra está repleta dos mais incomparáveis objetos de atenção e exercício infantis. E dos mais apropriados. Ou seja, as crianças são inclinadas de modo especial a procurar todo e qualquer lugar de trabalho onde visivelmente transcorre atividade sobre as coisas. Sentem-se irresistivelmente atraídas pelo resíduo que surge na construção, no trabalho de jardinagem doméstico, na costura ou na marcenaria. Em produtos residuais reconhecem o rosto que o mundo das coisas volta exatamente para elas, e para elas unicamente. Neles, elas menos imitam as obras dos adultos do que põem materiais de espécie muito diferente, através daquilo que com eles aprontam no brinquedo, em uma nova, brusca relação entre si. Com isso as crianças formam para si seu mundo de coisas, um pequeno no grande, elas mesmas" 2
\end{abstract}

Contra a domesticação de impulsos e contra uma concepção iluminista do ensino como enriquecimento e capitalização de saberes, em Benjamin, experiência pobre, in-fância e brincadeira estão inextricavelmente associados (como mostrara Agamben em Infância e história). Se os materiais "nobres", combi-

\footnotetext{
2 BENJAMIN, Walter. Rua de mão única. Trad. Rubens Torres Filho. São Paulo: Brasiliense, 1987,
} p. 18-19. 
nados logicamente e organizados numa grade curricular, numa pauta, e num programa, podem produzir na educação tradicional alguma "invenção" tímida, alguma crítica literária; os materiais do canteiro de obras, da "caixa de costura" (que é a sua versão matriarcal) ou, para as crianças do século XXI, todo aquilo que vai para o lixo seco, são os elementos mais propícios para construir "super-invenções" - como diria Helena nos seus quatro anos, ou "arqui-invenções", aventaria Raúl - objetos surrealistas que não são montados pensados em sua "propriedade", que não são exclusivos para um público alvo.

No canteiro de obra dos textos, nas montagens discursivas ou ficções críticas, ou seja, nas "super-invenções" de Raúl Antelo, entram também materiais diversos, porém geralmente apanhados de arquivos raros ou de zonas raras dos arquivos canônicos. Os materiais de "descarte" (que ele menos "resgata" e mais, "des-olvida", "des-esquece") são os materiais da erudição: só que os dados eruditos vão desbotando os carmins de nobreza que lhes estampam os historiadores e os filólogos tradicionais, para ganhar outra coloração, mais afetiva, a do um gesto artesanal, obcecado e infantil - via Benjamin - na lida com o arquivo.

Ora, que o professor brinque com os materiais, que se divirta, como ele mesmo diz em entrevistas, ou que simplesmente viva, que faça experiência e não que a possua nem a comunique ${ }^{3}$, torna menos simplificável a questão do exemplo. Para o aluno: sem tabuleiro de direções para apreender as regras, se jogar na brincadeira posta não é uma tarefa pouca, principalmente quando as posições pré-concebidas de sala de aula se orientam pela certeza de que, colação mediante, vai-se dominar o jogo. Como diz Antonio Carlos Santos em texto apresentado em outra homenagem ao Raul, organizada por Susana Scramim em 2010, há um grande desconcerto dos alunos frente à ausência de "conteúdos" e de respostas firmes, e frente à lição mais encenada e "martelada" -canteiros de obra - que diz que o objeto não existe e que o sentido só é dado pela leitura da série, infinita; e justamente por isso, por essa perda dos fundamentos acadêmicos antes de adquiri-los, ninguém sai indiferente desses encontros, "é um acontecimento, um fulgor, um relâmpago [...] Sua aula é a experiência do impossível, um dom". ${ }^{4}$ Sem presente, sem herança, o que predomina nesse jogo da sala de aula é a ruína dos equilíbrios corporais, ou, como diria Caillois, a vertigem (Ilinx). ${ }^{5}$

\footnotetext{
${ }^{3}$ Como diz Alexandre Nodari em "Raúl Antelo: Fazer a história": "o que ele "ensina" não é como se apropriar de um objeto, não é um "método" em sentido estrito, o que ele "ensina" é que só uma experiência singular e irrepetível com o objeto interessa, só ela faz história, história que não se pode acumular, herdar ou transmitir, mas apenas viver." Cultura e Barbárie, 6 mar. 2010. [Arquivo digital Consenso, só no paredão do blog da editora].

${ }^{4}$ SANTOS, Antonio Carlos. Acefalia e ética na crítica de Raúl Antelo. In: SCRAMIM, Susana (Org.). O contemporâneo na crítica literária. São Paulo: lluminuras, 2012.

${ }^{5}$ CAILLOIS, Roger. Los juegos y los hombres. Las máscaras y el vértigo. Trad. Jorge Ferreiro. México: Fondo de Cultura Económica, 1986.
} 
Desde o primeiro embate com essa prática sistemática da vertigem erudita e deshierarquizadora, a marca é a do fim da compreensão e da interpretação, apostando em outro tipo de prática intelectual - aesthetica e inebriante -, como a única possível para o pensamento dos filhos sem pai, latino-americanos (quando latino-americano é menos um lugar ou uma identidade do que uma posição ética), para os quais o objetivo é a de reapropriar-se da experiência infante, recuperar o balbucio e a potência da ecolalia, riscar a esperança no progresso. A condição é riscar as pretensões iluministas com sua própria arma: o estudo. A condição é assumir que nosso entre-lugar de partida nos caracteriza: assumir a modernidade periférica, como diria Beatriz Sarlo, ou como parece pensar Raúl as sobras da modernidade.

\section{DA ALIMENTAÇÃO DAS CRIANÇAS}

A tentação do prazer. A tentação é comer direto na fonte. A tentação é comer direto na lei. E o castigo é não querer mais parar de comer, e comer-se a si próprio que sou matéria igualmente comível

Clarice Lispector, A paixão segundo $G H$.

Hora de comer restos, sobras, é domingo no jantar. Porém, na nossa sala de aula, mais uma vez se tensiona a lógica produtiva e reprodutiva, tensão porque o ritual parece repetir as fórmulas tradicionais, um professor a simples vista da antiga escola, conferencista, de aparência impecável, pontual, preparadíssimo, rigoroso, erudito, sem improvisos. Porém, a reformulação a da radical acefalidade, pois da cabeceira da mesa, ninguém dirige a oração. Longe da repetição, "a acefalidade é um entre-lugar crítico" - diz Raúl em "El crítico inter es" que abre Crítica acéfala - e a sala de aula o reflete menos porque critique e mais porque ali se instala uma crise, ou se deflagra. O enfrentamento com esse vazio com o projeto iluminista que alicerça quase toda aula, a pesar de tudo estar aparentemente no lugar, dilacera o aluno, angustia. Mas como diz Raúl, "el crítico que no se angustia no me interesa". ${ }^{6}$

Evidentemente o que está em jogo não é uma noção iluminista de aluno, que parte, justamente da figura do aluno como o des-iluminado e do professor, mentor, tutor (ou o nome que tiver) como iluminador metódico, que baseia sua atividade numa experiência comunicável. Pelo contrário, ruída a ideia de formação, em tempos de desaparição da máxima e do provérbio, "as formas nas quais

${ }^{6}$ ANTELO, Raúl. Sobre escritura, delirios y sensibilidades. Entrevista con Josimar Ferreira, Lúcia Bahia y Sandra Checluski. Interartive: a platform for contemporary art and thought, abril 2014. 
situava-se a experiência enquanto autoridade", o desafio é driblar também o slogan que os substituiu, como diz Agamben em Infância e história, ${ }^{7}$ driblar de certo modo a cultura pop e o jeito cool de ensinar (já que a acefalia aqui não passa por desarrumar as cadeiras da sala aula).

Isto, no entanto, longe de ser uma ruptura nas práticas educativas, parece ser mais uma tentativa de montar outra cena/série pra a educação, utilizando seus restos etimológicos. Lemos, no dicionário etimológico de "termos usuais na praxis docente", escrito por Luis Castello e Claudia Mársico, da Universidade de Buenos Aires, uma arqueologia da palavra aluno:

\begin{abstract}
§ 22. Aluno
Em geral, chamamos 'aluno' ao sujeito que estuda no âmbito de uma instituição. $O$ termo foi, curiosamente, objeto de uma explicação etimológica disparatada que o faz derivar de um suposto a 'não' - remetendo a um alfa privativo próprio do grego - e lumen 'luz'. Aluno seria 'o que não possui luz', 'o que está no escuro', e que, portanto, busca "iluminar-se" mediante o estudo. Essa explicação, decerto, não resiste à menor análise histórica ou lingüística. Basta pensar que teria que se tratar de um composto híbrido que apresentaria uma raiz puramente latina -lumenunida a um prefixo privativo grego - $a-$. A rigor, o termo 'aluno' está aparentado semanticamente ao verbo educar ( cf. $\S 1$ ). Viu-se que uma das etimologias ligadas à idéia de educar se relaciona com 'alimentar'. Não é de se estranhar, então, que aquele que recebe o alimento seja o 'aluno'. Precisamente essa é a acepção do termo latino alumnus, que assim como alimentum, está formado a partir da raiz al, encontrada no verbo alere, 'alimentar'. Alumnus tem, pois, uma primeira acepção de 'criança', literalmente 'o que é alimentado', e outra derivada e abstrata que ganha o sentido de 'discípulo' (cf. § 24).
\end{abstract}

\title{
[Observações
}

1. Há casos claríssimos da existência de híbridos nas línguas modernas; basta citar, como exemplo, 'automóvel', construído sobre a base do termo de origem grega autós 'si mesmo', 'por si mesmo' e o de origem latina mobilis 'móvel'. No entanto, é preciso notar que esses casos costumam ser sempre construções tardias e nunca elaborações próprias da língua. O caso de 'automóvel', certamente, se ajusta a esse padrão, enquanto que em 'aluno', são seguidos os parâmetros de evolução lingüística da passagem do latim ao português.

2. Da mesma raiz *al provêm, ademais, por um lado, o adjetivo latino altus, 'alto', 'profundo', 'crescido', de onde 'enaltecer', 'exaltar'. Por outro lado, as formas compostas aboleo e proles. No caso de aboleo 'atrasar o desenvolvimento de', donde

\footnotetext{
7 AGAMBEN, Giorgio. Infancia e historia Trad. Silvio Mattoni. Buenos Aires: Adriana Hidalgo, 2004, p. 9-10. "Porque la experiencia no tiene su correlato necesario en el conocimiento, sino en la autoridad, en la palabra y el relato. Actualmente ya nadie parece disponer de autoridad suficiente para garantizar una experiencia y, si dispone de ella, ni siquiera es rozado por la idea de basar en una experiencia el fundamento de su propia autoridad. [...] de allí la desaparición de la máxima y del proverbio, que eran las formas en que la experiencia se situaba como autoridad. El eslogan que los ha reemplazado es el proverbio de una humanidad que ha perdido la experiencia."
} 
nosso 'abolir', trata-se da raiz com o prefixo ab. Proles, 'estirpe', 'descendência', por sua vez, está construída com o prefixo pro- e dá lugar aos derivados 'proletário' -proletarius-; 'prolífero' -composto de proles e fero 'levar'- e 'prolífico' -de proles e facio 'fazer'-.].

Alunos alimentados, profusamente. O educador Antelo, de um século de trevas mas formado na cultura das luzes, coloca tanta comida na mesa que nos instiga à compulsão, à glutonaria, ao excesso. Incitando distúrbios alimentares como os da filologia, aquela musa bulímica (uma "traga") da qual nos fala Daniel Link. ${ }^{8}$ Próximos da antropofagia como exercício ético em sala de aula, o desafio e a tentação é "comer direto na lei" - matar o pai - só que a lei é ao mesmo tempo autofágica e está na nossa frente. Tentação e castigo, proposta e impossibilidade: "A tentação é comer direto na lei. E o castigo é não querer mais parar de comer, e comer-se a si próprio". Não é ameno, nos obriga à pergunta pela relação estabelecida, o que é ser/estar professor o que é ser/estar aluno?

Dos verbos vinculados à tradição da ilustração, o professor contemporâneo exerce poucos. Não instrui, não forma, não domestica, não oferta algo que tem para alguém que não tem. Não ensina: não escreve o Nome, o sinal, o signo que deveríamos seguir, não em-signa. Não guia, não prepara, não ilustra, não ilumina (ou ilumina de forma intermitente e vandalizante, já que faz do "gato", das ligações clandestinas, o seu modus operandi). Muito menos impõe, doutrina, ou admoesta. Não exercita, porque definitivamente não tem exército, nem fieis (se tiver, tenho para mim que não os quer, não desse modo). Talvez transmita, não um conteúdo, mas o gesto da transmissão, do envio derridiano, do deixar ir. Talvez facilite, não porque simplifique as suas questões, mas porque permite, diz "pode, fazer". 9 Porém, exerce um, sempre, educar: traz as pastas cheias de alimento. Exigindo em troca que se chegue com fome. E já não surpreende a metáfora alimentícia - associada ao canteiro de obras - quando Raúl é perguntado pelo trabalho docente:

Como eu não tenho nenhuma confiança na evolução, no historicismo, no gradualismo ou que nome tenha, entendo que a história é violenta e abrupta, nos arrebata para além dos projetos ou vontades que possamos ter. Não tenho a confiança pedagógica de que hoje vamos ler um autor da página tal à tal e amanhã tem outro autor e, gradativamente, tijolo após tijolo, iremos construindo a casa. Acho que já houve o terremoto, que a casa que pudermos construir será a partir dos

\footnotetext{
8 Apresentação da palestra "Postfilología y neohispanismos: apuntes sobre el futuro de una disciplina", VIII Congresso Brasileiro de Hispanistas, set. 2014.

9 Neste sentido, cabe apontar que não se aproxima a figura deste professor erudito, que não deposita um conteúdo à articulada por Rancière, em $O$ mestre ignorante em relação a Jacotot.
} 
escombros sobre os quais estamos parados [...] Tomo como um teste de avaliação do desejo se, diante da primeira dificuldade, a pessoa desiste ou diz que não entende, pede que explique direitinho, primeiro o A depois o B. Digo: bom não está suficientemente atravessado pelo desejo, se estivesse já teria arrumado outras formas de suprir essas lacunas, porque lacunas todos temos, toda nossa formação é lacunar, o saber é lacunar. [...] Sou impaciente e exigente com determinados dados mínimos, não vou dar, não vou servir a comida de bandeja, vire-se, o estoque está aí, mova-se. Acho que isto se deve, talvez, à maneira como me eduquei, sempre fui muito voraz com a biblioteca do meu pai, das escolas por onde passei, das bibliotecas públicas do meu bairro, ou onde fosse. Tinha uma especial voracidade pelos livros situados onde ninguém alcança e os que ninguém abriu. ${ }^{10}$

Não servir a comida de bandeja quer dizer que o estoque está ai, jogado (colocado em jogo), não classificado, ou precisando ser desclassificado. Sendo assim não importa a nobreza das comidas no que elas têm por características próprias, mas as combinações nas quais elas entram. Estarrecendo expectativas de sofisticação do cardápio, o professor alimenta-se dos livros marginais, dos cascalhos inusitados dos arquivos: não das obras, mas das sobras, do que ninguém quis. Ele quer, trata-se de amor. Pois a sua erudição - talvez toda erudição - se faz muito mais de restos que de cânone.

Educar apátridas sem bandeja de prata e sem porcelanas proibidas, mas com o compromisso - matriarcal11 - de "parar la olla".

${ }^{10}$ ANTELO, Raúl. Um intelectual de extimidades. Palíndromo: Teoria e História da Arte, n. 3, p. 257, 2010. [Entrevista concedida à Prof. Rosângela Cherem].

11 Duas referencias: por um lado, se "parar la olla", comumente se associa à idea de fornecer sustento econômico, atividade tradicionalmente masculina, a idea adquire um vínculo muito mais forte em grupos sociais onde sem ter sustento econômico garantido, são as mulheres, de modo coletivo, as encarregadas de encher as panelas, com comidas, aproveitando restos. As "ollas populares" surgem, na maioria dos casos, em América Latina, também como atividade feminina, inicialmente de ajuda mútua e comunitária, que pretende romper com a estrutura de assistencialismo Estatal, isto é, patriarcal (Cf. ALARCÓN, Cristian. Cuando me muera quiero que me toquen cumbia. Buenos Aires: Norma, 2004, p. 15. No dia a dia da "villa", o antropólogo observa: "Las madrazas en busca del faltante para resolver el hambre secruzaban de vereda a vereda rescatando porciones a reciclar con una pericia que evidenciaba elentrenamiento en la faena de llenar la olla del día." (Cf. também RICHER, Madelaine. Comedores populares, ollas comunes y cocinas coletivas, Fermentum, n. 28, mayo-ago. 2000). Por outro lado, a prática docente de Raúl já foi associada à construção do matrarcado por Alexandre Nodari em "Rául Antelo: fazer a história". Ele comenta o comentário de Eneida de Souza: "Eneida chamou a atenção para a heterogeneidade das abordagens e dos trabalhos dos ex-orientandos, observando que via ali uma relação não entre Pai e filhos, mas, talvez, entre tio e sobrinhos. A aparente simplicidade do comentário pode esconder a sua profundidade: mas, de fato, nele, Eneida captou o que está em jogo no trabalho de Raúl Antelo - a construção do Matriarcado. O Matriarcado não é o domínio das mulheres, o Matriarcado é a organização social baseada no filho do direito materno, isto é, na qual quem exerce a figura do "Pai" não é o que concebe, mas o irmão da mãe, o tio. O Matriarcado representa a abolição do Patriarcado, e de tudo que deriva dele: a autoridade, a propriedade, a herança - e, com ela, a tradição". 
Ali aparece outra imagem que Raúl levanta dos restos ibéricos do século $X X$. Na sua leitura de Eugenio D'Ors, ou melhor, na leitura que faz de Eugenio D'Ors para falar e ao mesmo tempo de Latino-america, da poesia e da necessidade de outras formas de ler, destaca a avaliação obliqua da pintura de Goya, na qual D'Ors observa, como traço principal, o estado de ruína, mas do prazer que essa ruína pode proporcionar. Raúl cita D’Ors:

\begin{abstract}
"OLLA PODRIDA". - Sí, las obras de Goya son, tectónicamente, una ruina. Pero son una ruina sabrosa. El mismo fraccionamiento, la misma mescolanza, la misma incoherencia íntima de las intenciones, parece dar a cada elemento, a cada fragmento, a cada tropezón de materia pictórica, el máximo de su intensidad, el máximo de su calidad voluptuosa. Y aquí, al considerar con simpatía, con los sentidos bien abiertos, el secreto de esa estructura, el término definitorio, se nos viene a la imaginación sin esfuerzo. Nos llega, (puesto que ya de sabores se trata, puesto que aquí el gusto se fabrica un goce en la misma interior contradicción sensorial) el recuerdo de estos guisotes de la cocina popular y castiza, donde también la multiplicidad es ley y la abigarrada contradicción de elementos, la multipolaridad de intenciones, la alternativa entre la fluidez y la consistencia, entre el grano minúsculo y el recio tropezón. El recuerdo de estas paellas, estos pucheros, estas "ollas podridas" de la mesa hispana, donde todo se junta y revuelve: lo cocido, lo crudo, lo semicrudo, la carne y el pescado, la lo salsero, los huesos y los caldos, lo íntegro y lo trinchado, en divertida, y gruesa, y a la vez delicada suscitación salivera de la multiplicidad. [...] Advirtamos que la reacción gustativa en el caso imaginado, no sería otra cosa que la aplicación a dominio apenas distinto de las reacciones que en nuestra sensibilidad se producen con la contemplación de las obras goyescas.
\end{abstract}

Parafraseando D'Ors nos comentários sobre a pintura, poderíamos dizer que "também para a sala de aula há uma gula, também para os fragmentos de texto há uma fome específica" que provoca não uma reação salivar concreta, mas uma vontade de "atender" - escutar e esperar sem esperança. A "olla podrida" é mais uma imagem - do tipo do canteiro de obra - que concebe a arte, a linguagem e o texto, a partir das suas relações e não das suas identidades, a partir do que eles são capazes de mobilizar, na qual os sentidos (o sensato e os sensoriais) se misturam sinestesicamente produzindo atritos e choques interiores. A digestão deste "prato principal", prato único que aproveita e mistura tudo, é difícil, diz D'Ors, mas sempre terá "um ar de festa"12 - a tentação e o castigo da comida - festas que, como diz Caillois "também são pontes".

A literatura argentina do século XIX, feijão com arroz da (de)formação argentina, encenou de forma consistente a relação com o outro, e as possibilidades

${ }_{12}$ ANTELO, Raúl. Cinco minutos de silêncio, Remate de males, v. 34, n. 1, p. 21-41, jan.-jun. 2014; D'ORS, Eugenio. Tectónica goyesca. Notas concretas y precisas. Blanco y Negro, ABC, a. 38, n. 1926, 15 abr. 1928. 
de constituir uma república ou não, da possibilidade de "iluminar" o povo escuro, referindo-se aos estômagos. O coronel Mansilla, nas suas causeries (1989-90) parte da reformulação do ditado popular: "Dime lo que comes y te diré quien eres" em um evidente afã modernizador que antes, na sua Excursión a los indios ranqueles (1870), se traduzia na utilização de comida como barganha para negociar com índios e ir avançando territorialmente. Anos antes, ainda, no texto considerado primeiro conto argentino, "El matadero" (1938-40), os estômagos dos grupos sociais ali em conflito são personagens centrais concentrando as descrições naqueles que não são capazes de controlar seus corpos desobedecendo à quaresma: assim, todos, de "las negras rebusconas de achuras" até os gringos que reclamam seu "beefsteak", são rapidamente colocados no lado de lá da civilização. Assim como os índios, outros radicais definidos por Echeverría pelo seu modo de comer no "fundador", La cautiva (1937).

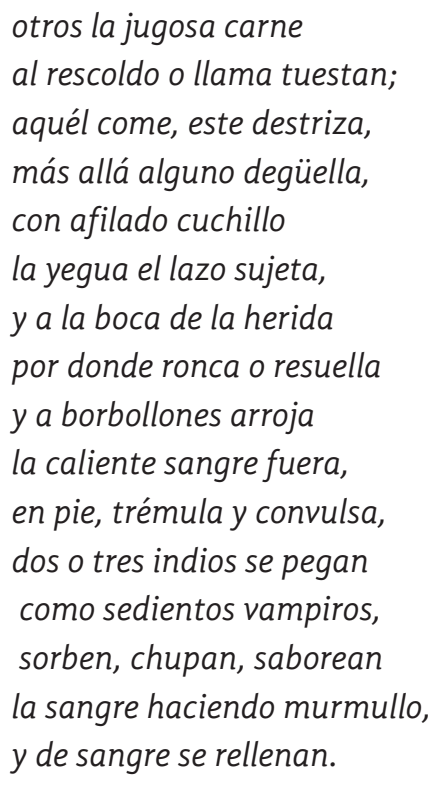

Nestes textos o fato de apontar outros hábitos alimentares é uma tentativa classificatória, de demarcação de fronteiras, mas que a atração do olho observador, seu fascínio vertiginoso, passa a colocar em questão. Chegando ao ponto culminante, no momento em que se come o alimento do outro - que sempre se pensa como nojento - onde o outro é tocado e o próprio estômago passa a ser um tumulto anárquico de identidades (rebelião, festa). Como vemos no próprio o coronel Mansilla, que senta com os índios para beber e comer a comida deles e acaba enfastiado, passando mal, e tendo sonhos onde ele e o cacique Calfulcurá se misturam tanto quanto os ingredientes de um guisado. Ou em Sarmiento, 
que tentava separar claramente civilização e barbárie, mas que na sua viagem pela África sofre um importante abalo tendo que experimentar a comida na diffa. Na verdade, Sarmiento pode ser definido como o faz David Viñas como um "escritor glotón", cuja glutonaria - um fascínio pelo excesso, por Facundo, pela barbárie, pela comida - seria a linha de fuga de um programa de controle, da sua procura por um método. Assim, Sarmiento elogia os grandes bandejões americanos por seu sistema organizado, metódico, porém fica estarrecido e encantado com os pratos imensos de comidas incompatíveis que as pessoas ali montam: "Qué incongruências! Qué incestos, i qué promiscuaciones en los manjares! Patatas con vinagre! [...] los pecados de Sodoma i Gomorra debieron ser menores que los que cometen a cada paso estos puritanos!"13 Quer método contra a barbárie, mas sua fome é por ela.

Como uma "olla podrida", ou uma "feijoada", "se a literatura latinoamericana é", diz Raúl, "uma ruína saborosa, é porque, em todo gesto de emergência do novo, tal como na estrofe gauchesca, predomina um gesto, ao mesmo tempo, principiante e epilogante", ${ }^{14}$ em toda tentativa de separação um rejunte, em toda dicotomia um ponte e uma festa.

\section{DO RISCO LATINO-AMERICANO}

No primeiro texto de Crítica Acéfala, "El guión de extimidad" - talvez um dos seus textos, se algo assim existir, mais programáticos - Raúl Antelo se instala no traço, entre-lugar, que separa e junta o argentino-brasileiro (como para Derrida em "O monolinguismo do outro", o drama da linguagem se encontrava no argelino-maghrevi).

A princípio quem escuta o Raúl pode se enganar pela sua ausência de sotaque, pode achar que ele se instala ora num ora noutro lado, como se ele respeitasse os tradicionais blocos linguísticos, nacionais. De fato, algumas semanas atrás, quando perguntado em um encontro argentino-brasileiro pelo motivo que o levava a falar em português, sendo que falava para um público dividido e onde todos compreenderiam o seu espanhol materno, Raúl deu uma resposta não facilmente digerível. Uma resposta a contramão de uma escolha pelo sotaque, pela minoridade da língua, que a maioria dos que atravessamos a fronteira performamos, um pouco por falta se talento outro pouco pela necessidade de ouvir os restos da outra língua na nova língua, e a contramão de investimentos

\footnotetext{
${ }^{13}$ SARMIENTO, Domingo Faustino. Estados Unidos. Viajes por Europa, Africa i América 18451847. Fondo de Cultura Económica, Colección Archivos: Madrid, 1993. [En forma de carta a Valentín Alsina].

${ }^{14}$ ANTELO, Raúl. Cinco minutos de silêncio, op. cit., p. 39-40.
} 
fortes no cruzamento e contrabando fronteirizo, que ele celebra. Raúl diz que o que o leva a escolher é a língua do Estado. No Brasil português, na Argentina espanhol. A resposta choca porque vem de alguém que desconfia do Estado, da língua pátria.

Como entendê-la, então? Talvez uma forma de desfazer o incômodo seja ir mais a fundo na radicalidade do traço, do guión. A ausência de sotaque, a perfeição em duas línguas, não deixa de apontar para a língua ausente: causa surpresa, espanto, pergunta. Assim, longe de apagar o risco, o torna mais definitivo. Como se em português riscasse o espanhol, em espanhol riscasse o português. E nessa rasura, nessa "tachadura", que tanto apaga quanto fixa, com uma tacha, quando aparece o contato paronomástico, o erro de uma língua na outra como queria Wilson Bueno, a linguagem agita toda a potência de sua abertura heterológica, sua multiplicação. Como diz Raúl-com-Derrida em "Para uma archifilología latinoamericana": "Ya que es propio del lenguaje desdoblarse en espejo y convocar lo equívoco ("as lagostas são caríssimas, caríssimas súbditas"), o errar en intensidad (Cleopatra o Cleópatra), siempre corresponde a una lengua invocar la apertura heterológica que le permita hablar de otra cosa y dirigirse al otro,". ${ }^{15}$ Em outras palavras, nessa rasura das línguas aparece com mais força a poesia, que vem "para multiplicar e não para reproduzir sentidos", ${ }^{16}$ como ele diz se referindo à ideia mallarmaica de poesia como compensadora do defeito das línguas.

Riscar para abrir é o método de juntar línguas e de juntar literaturas. Tradicionalmente os estudos comparativos limitam-se a comparar por semeIhanças ou diferenças blocos concebidos como homogêneos. Porém a obra do Raúl insiste em percorrer outro tipo de fluxo, concentrado no traço, no entre. Ele diz, em 1998, diagnosticando o fim do comparatismo como disciplina disciplinada na própria revista da ABRALIC: "a literatura comparada é a teoria da guerra e [...], ao mudar o cenário e o objeto das lutas, (não mais o indivíduo, não mais o valor, não mais a disciplina, não mais a nação) o específico da literatura comparada, nos dias de hoje, é sua passagem ao ato, sua dissolução, sua transgressão, seu movimento ao exterior de si". ${ }^{17}$ Dali que ele insista em fazer leituras transatlânticas de Europa, em comparações por vieses inusitados,

\footnotetext{
15 Idem, Para uma archifilología latianoamericana. Cuadernos de literatura, v. xvii, n. 33, p. 265, ene.-jun. 2013.

${ }^{16}$ Idem, La traducibilidad posfundacional. In: CÁMARA, Mario; LEONE, Luciana di; TENNINA, Lucía (Comps.). Experiencia, cuerpo y subjetividades: nuevas reflexiones. Literatura argentina y brasileña del presente. Buenos Aires: Santiago Arcos editor, 2011, p. 132.

17 Idem, Liminar. Revista da ABRALIC, v. 4, p. 7-9, 1998.
} 
quando não inusitadas elas mesmas, e na comparação nunca de "literaturas nacionais", já que o gesto é sempre o de aproximar o distante e afastar o próximo, montar cenas de pensamento como, segundo Rancière, "pequenas máquinas óticas que nos mostram o pensamento ocupado em tecer laços, afetos, nomes e idéias e em constituir a comunidade sensível que esses laços tecem e a comunidade intelectual que faz pensável esse tecido". ${ }^{18}$ Ler Maria Martins com Marcel Duchamp, ler Alejandra Pizarnik com o sacer, ler cenas da vida cultural com o regime de visibilidade dos modernismos, Caillois com Vitoria Ocampo, onças com Vilém Flusser, a sextilha da gauchesca com Eugênio d'Ors, e tantos etcéteras quanto textos ele já preparou. Atravessamentos que são encenações de "modulações da guerra nômade", nômades se movimentando por um mar paraguayo, o "território" mais representativo dos trânsitos do Rául, dos nossos trânsitos? (Ai quem me dera ser a máquina de guerra!). Dai que a obra - a sobra - de Raúl seja ao mesmo tempo infinitamente babélica e profundamente fincada em latino-america.

Mas voltemos pois a questão continua sendo a educação e o que se funda, o que pode ser fundado, no risco. No belíssimo "La traducibilidad posfundacional", que parte da interrogação pela re-escrita da mitologia tupinambá levada adiante por Alberto Musa em Meu destino é ser onça (2009), Raúl mostra como, no livro, desafia-se a possibilidade de reunir, gênese e estrutura, mythos e logos, no gesto de (re)escrita ao mesmo tempo ficcional e ensaística, original e apócrifa, pelo qual a palavra ativa a potência do aparato mitológico, não mais em busca de um sens como sentido primigênio, mas como uma ab-sens ou non-sense. ${ }^{19}$ Nesse ponto, não é possível achar nem ensinar, via mito, uma fundação totêmica, nem reconstruir uma linhagem genética, mas produzir uma disseminação, produzir uma origem disseminada no tempo (ou fazer a história, como diz Alexandre Nodari em relação ao método do Raúl). As palavras não como pedras capitais ou preciosas, mas como pedras plebeias (como o arenito, como a brita de construção ou como as rosas do deserto, que encantavam o "menino" Caillois) que nas suas vetas anárquicas deixam ler uma proto-história. Tempo da rasura, do pós-fundacional (que não é, o antifundacional) que Raul percorre perseguindo a onça, perseguindo o jaguaretê em diversos textos latino-americanos, excedendo o âmbito nacional. A fundação continua estando em pauta, porém apenas como interrogação dos seus diversos rostos e, no seu lugar a tradução, a tradutibilidade, como pós-fundação - um canteiro de obras, um futuro arcaico - torna-se o único trabalho possível. A pedagogia (im)possível para estes filhos.

${ }_{18}$ RANCIÉRE, Jacques. Aisthesis. Trad. Horacio Pons. Buenos Aires: Manantial, 2013, p. 11.

19 ANTELO, Raúl. La traducibilidad posfundacional, op. cit. 
Cuando yo era chica, solía acompañar a mi papá, arquitecto, cuando él tenía que supervisar las obras en construcción. Desde entonces, el olor a cemento armado en preparación, el ruido de las mescladoras y de los martillos, pasaron a hacerme acordar de mi infancia, cada vez que pasaba por una obra de barrio. El olor a cemento, mi madelaine. Ahora, años después, en otro país, no qual eu não passo mais por "obras en construcción", mas por "canteiros de obra", o cheiro de cimento me lembra, riscando a língua do meu pai com a língua da mina filha, riscando e tachando, rasurando e pregando, soltando e fixando; agora, digo, o cheiro de cimento dos canteiros de obra continua me lembrando da minha infância, mas também do meu futuro, de todo e de nada; lembro de como os pais sempre faltam, mesmo estando. Lembro das duas coisas que eu aprendi com Raúl. 